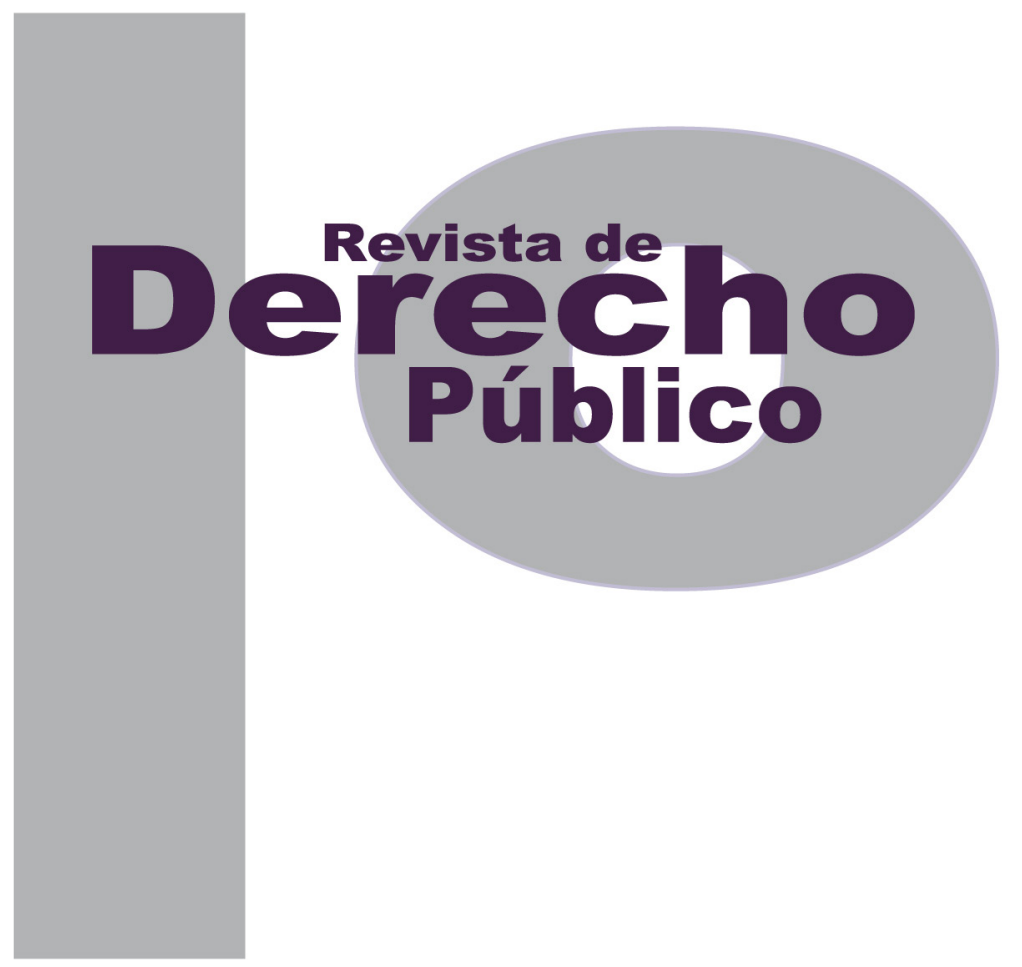

DERECHO EN LA LITERATURA: DERECHO Y CONTROL SOCIAL EN LAS NOVELAS 1984 Y 1 Q84

\author{
MARIBEL MENDOZA LONDOÑO
}

Artículo de reflexión

DOI: http://dx.doi.org/10.15425/redepub.36.2016.05

Universidad de los Andes

Facultad de Derecho

Rev. derecho publico No. 36

enero - junio de 2016. e-ISSN 1909-7778 


\section{Derecho en la literatura: derecho y control social en las novelas 1984 y $1 Q 84$}

\section{Resumen}

Este texto se acerca al derecho a partir de la literatura, a través del estudio de las novelas 1984, de George Orwell y 1Q84, de Haruki Murakami, obras que plantean problemas acerca del control social, relevantes para la teoría jurídica. Se estudia la respuesta que dan ambas novelas al problema jurídico: ¿Cuáles son los límites del derecho para ejercer y mantener el control social? El documento evalúa los conceptos de validez y justicia y legitimidad y autoridad en el contexto de las sociedades antidemocráticas que presentan las dos obras, para determinar cuándo han de ser las normas obligatorias. Analiza la relación que existe entre verdad y proceso judicial para determinar cuál es el fin de la pena y su uso como mecanismo para mantener el control. Se examina la relación entre ordenamiento jurídico, estructura social y control, para establecer si la división social en estratos contribuye al mantenimiento del orden o si, por el contrario, crea tensión y rebeldía entre los individuos.

Palabras clave: derecho y literatura, derecho en la literatura, teoría del derecho, subversión crítica, control social, orden social, totalitarismo, represión, validez formal y material de las normas, justicia, legitimidad de la autoridad, proceso judicial y fin de la pena, estructuralismo social.

\section{Law in literature: law and social control in the novels 1984 and $1 Q 84$}

\section{Abstract}

The purpose of this text is to approach law from literature by studying the novels 1 Q84 from Haruki Murakami and 1984 by George Orwell, works that raise issues about social control, relevant to legal theory. This project examines the answer that the novels give to the following legal problem: which are the limits of law to exercise and maintain social control? The document studies the concepts of "validity and justice" and "legitimacy and authority" within the context of the anti-democratic societies in the novels, to determine which laws are to be mandatory. It analyses the relationship between "truth and judicial process" to study the "end of sentence" and if is a mechanism to maintain internal control. It examines the relationship between "legal system, social structure and control" within these totalitarian societies, to establish whether the form of social division in stratus contribute to the maintenance of order or if instead it creates tension between individuals generating rebellion.

Keywords: Law and literature, theory of law, social control, social order, totalitarianism, repression, formal validity and material standards, justice, legitimacy of authority, judicial process and purpose of punishment, social structuralism.

\section{Direito na literatura: direito e controle social nos romances 1984 e $1 Q 84$}

\section{Resumo}

Este texto se aproxima do direito a partir da literatura, através do estudo dos romances 1984, de George Orwell e 1Q84, de Haruki Murakami, obras que propõe discutir problemas acerca do controle social, relevantes para a teoria jurídica. Estuda-se a resposta que dão ambos romances ao problema jurídico: Quais são os limites do direito para exercer e manter o controle social? O documento avalia os conceitos de validez e justiça e legitimidade e autoridade no contexto das sociedades antidemocráticas que apresentam as duas obras, para determinar quando estas têm de ser as normas obrigatórias. É analisada a relação que existe entre verdade e processo judicial para determinar qual é o fim da pena e seu uso como mecanismo para manter o controle. Examina-se a relação entre ordenamento jurídico, estrutura social e controle, para estabelecer se a divisão social em estratos contribui à manutenção da ordem ou se, pelo contrário, cria tensão e rebeldia entre os indivíduos.

Palavras-chave: direito e literatura, direito na literatura, teoria do direito, subversão crítica, controle social, ordem social, totalitarismo, repressão, validez formal e material das normas, justiça, legitimidade da autoridade, processo judicial e fim da pena, estruturalismo social. 


\title{
Derecho en la literatura: derecho y control social en las novelas 1984 y $1 Q 84^{*}$
}

\author{
MARIBEL MENDOZA LONDOÑO ${ }^{1}$
}

\section{SUMARIO}

Introducción - A. 1984, de George Orwell - B. 1Q84, de Haruki Murakami - I. VALIDEZ FORMAL Y MATERIAL DE LAS NORMAS: NORBERTO BOBBIO Y SU OBRA TEORIAA GENERAL DEL DERECHO - II. VALIDEZ Y JUSTICIA DE LAS NORMAS: FÓRMULA RADBRUCH - III. PROCESO JUDICIAL, PENA Y CRIMINAL - A. Proceso judicial y verdad - B. Fin de la pena y criminal - IV. ESTRUCTURALISMO SOCIAL: WEBER Y EL MODELO TRIDIMENSIONAL DE ESTRATIFICACIÓN - V. CONCLUSIÓN - Referencias.

* Cómo citar este artículo: Mendoza Londoño, M. (Junio, 2016). Derecho en la literatura: derecho y control social en las novelas 1984 y 1Q84. Revista de Derecho Público, (36). Universidad de los Andes (Colombia). DOI: http://dx.doi.org/10.15425/ redepub.36.2016.05

1. Abogada con opción en Literatura, Universidad de los Andes. Correo: m.mendoza732@uniandes.edu.co 
Introducción

En la actualidad existen tres ejes de conexión entre el derecho y literatura, a partir de los cuales se han desarrollado los estudios e investigaciones que vinculan lo jurídico a lo literario (Talavera, 2006, pp. 10-60). Estas líneas de investigación han sido tradicionalmente conocidas con las denominaciones: el derecho como literatura, el derecho de la literatura y el derecho en la literatura. Esta última hace referencia a "la manera como la literatura imagina al derecho, esto es, al análisis de la forma como los textos literarios representan el mundo jurídico." (Bonilla, 2005, p. 100). Se estudia el derecho como tema central de muchas narraciones literarias, las cuales aportan valiosas reflexiones críticas acerca de los postulados normativos, su motivación, su origen, su validez, aplicación e interpretación.

Entonces, resulta importante para la teoría y la práctica jurídica el estudio de la literatura, pues en ella se evidencian temas relevantes para el derecho. Los diferentes personajes y argumentos desarrollados en la literatura

nos enfrentan con las paradojas de una legalidad sin legitimidad, de un derecho sin moral, de una injusticia legalizada (...) La literatura asume una función de subversión crítica, más allá del estricto marco de las disciplinas científicas y del conjunto de reglas y métodos de la hermenéutica que se imponen los juristas. (Talavera, 2006, p. 59).

La literatura no concibe el derecho de la misma forma que el jurista dogmático y por ello puede problematizar y criticar sus postulados y forma de creación, pues lo sitúa y lo evalúa fuera de su contexto tradicional. Lo expone a la luz de las preguntas más básicas pero importantes para el derecho: ¿Qué es control social y cómo ejercerlo?, ¿Qué es el poder?, ¿Cómo alcanzar la justicia?

Para Richard Posner (1998), autor del movimiento Law and Literature, la literatura no debe ser considerada una herramienta para el estudio de normas jurídicas. Esto debido a que carece de una perspectiva objetiva e imparcial de la realidad. Sin embargo, el autor reconoce que las obras literarias tienen un valor significativo para la creación del derecho, en la medida en que plasman una representación de la condición humana. Si bien es cierto que la literatura no tiene la capacidad de transformar a los seres humanos en mejores o peores ciudadanos, tampoco en juristas más éticos o jueces más justos, estas obras ofrecen a los lectores panoramas morales que sirven como instancia crítica del derecho. En ese sentido Robin West (1988) indica que la lectura de la ficción literaria constituye un proceso interactivo en el cual el lector interpreta del texto cómo solucionar diferentes problemas éticos y morales a los cuales se ven enfrentados los personajes. Por tanto, es la capacidad de empatía el instrumento del cual se vale la literatura para explorar y comprender los sentimientos que nos llevan a adoptar un determinado modelo de conducta, para luego contrastar estas actitudes con la forma en la cual atendemos a las reglamentaciones jurídicas. 
En la misma medida Nussbaum (2005) sostiene la idea de que la conexión entre el derecho y la literatura está fundamentada en dos elementos principales. El primero es la capacidad literaria de describir arquetipos universales, y el segundo es evocar un sentimiento de afinidad con los personajes a partir de las historias narradas. De allí que, para esta autora, la lectura de novelas es un método para evaluar las ideas de justicia y su aplicación dentro de la sociedad, a pesar de que la literatura no suministra respuestas exactas para los problemas de justicia social.

Por reflexiones como las de estos autores he decidido encuadrar este artículo académico en la tercera línea de investigación expuesta: el derecho en la literatura. La literatura constituye una ventaja para los abogados en la medida que les ofrece una perspectiva de realidades diferentes a la tradicional, donde pueden imaginar y construir soluciones a las cuales no llegarían si se mantienen dentro de los límites del derecho, puesto que este está dominado por una lógica teórica que ata al jurista a una dogmática predeterminada, la cual lo amputa de sus métodos de interpretación y su creatividad.

El propósito de este texto académico es acercarse al derecho a partir de la literatura, a través del estudio de las novelas 1984, de George Orwell y 1Q84, de Haruki Murakami, obras que plantean problemas acerca de la organización y control social, relevantes para la teoría jurídica y la filosofía del derecho. De allí que la investigación esté destinada a estudiar la respuesta que pueden dar las novelas 1Q84 y 1984 al siguiente problema jurídico: ¿Cuáles son los límites del derecho para la ejercer y mantener el control social?

He decidido desarrollar este documento en cuatro secciones principales. El objetivo específico de las dos primeras consiste en estudiar cuál es la noción de validez y justicia de las normas, en el contexto de las sociedades antidemocráticas descritas en las novelas 1984 y 1Q84, para determinar cuándo han de ser estas obligatorias. Para su estudio se tendrán en cuenta los postulados de Norberto Bobbio en Teoría general del derecho y la tesis sobre el derecho injusto de Radbruch.

La tercera sección tiene como propósito analizar la relación que existe entre verdad y proceso judicial, presentada en las novelas escogidas, para determinar cuál es el fin de la pena y si esta es un mecanismo idóneo para mantener el control interno. En este aparte se han de tener presentes los conceptos de autores como Kant y Feuerbach. La cuarta sección busca examinar el modelo de estructura social que impone el ordenamiento jurídico dentro de estas sociedades totalitarias, teniendo como base el modelo tridimensional de estratificación de Weber, para establecer si estas formas de división social contribuyen al mantenimiento del orden o si, por el contrario, crean una tensión entre los individuos generando en ellos rebeldía.

Estudiar estas obras resulta relevante para el campo del derecho ya que en ellas los autores 
describen regímenes totalitarios y antidemocráticos, donde los personajes están en una constante lucha entre obedecer las normas de convivencia colectiva o desobedecerlas en aras de proteger bienes jurídicos que a su juicio consideran superiores. Por tanto es posible extraer información que permita entender diferentes conceptos jurídicos como validez y justicia, legitimidad y autoridad, fin de la pena, y la relación entre ordenamiento jurídico, estructura social y su control. Este ejercicio nos permite entender aspectos centrales del mundo y la sociedad en la que vivimos.

\section{A. 1984, de George Orwell}

Publicada en 1949, la obra 1984 es una novela de ciencia ficción que describe una sociedad distópica ${ }^{2}$ comandada por la figura omnipresente y vigilante del Gran Hermano. Dentro de esta comunidad existen todo tipo de normas y mandatos que reprimen y controlan al ser humano; el resultado es que le es imposible autodeterminarse. De allí que en Oceanía el propósito del derecho es el de homogeneizar a todos los individuos que pertenecen a Ingsoc. Sin discriminar su género se pretende la igualdad incondicional con el objetivo de anular las ideas innovadoras y mantener la estabilidad.

Como ejemplos de las políticas que instaura el partido del Gran Hermano para controlar los individuos está el evitar que se cree una diferenciación entre ser hombre y ser mujer. El derecho busca abolir la noción de género como una categoría construida social, histórica y culturalmente. Es decir, no cabe la posibilidad de adoptar un estilo de vida individual basado en la identidad de género. ${ }^{3}$ Surge entonces la feminidad como un acto de rebeldía, es por esto que Julia, en el escondite,

se había pintado la cara. Debía de haber comprado maquillaje en alguna tienda de los proletarios. Winston nunca había visto ni se había atrevido a imaginar una mujer del partido con cosméticos en la cara. Lo más importante era que se veía infinitamente más femenina. - Estoy dispuesta a ser una mujer

2. Juan Manuel Santiago (2003), en la conferencia impartida durante la Feria del Libro de Cádiz de 2003, sostiene que Orwell, para proponer lo que debe entenderse como orden social ideal, construye una "distopía", concepto que define por oposición a la utopía. Y se remite a Las cien mejores novelas de ciencia ficción del siglo XX, publicación coordinada por Julián Díez, donde se explica que "utopía" corresponde a un estado de la humanidad donde cada persona tiene satisfechas sus necesidades y existe un gobierno benévolo que provee de todo lo necesario (o bien el gobierno ha desaparecido absolutamente, tras resultar innecesario). El nombre procede de la obra homónima de Tomás Moro (que viene del griego u topos, ningún lugar)." Corroborando con ello la idea de que Orwell redacta una sátira de una sociedad opresiva y cerrada donde un gobierno autoritario es quien controla a los individuos para transmitir al lector la necesidad de construir una sociedad democrática y sin división social.

3. Autores como Zoë Fairbairns difieren de este análisis. El aporte de esta escritora a esta compilación de bibliografía crítica de 1984 reside en que ella analiza a Orwell desde una perspectiva de género. En su ensayo "1984 came and went" (Fairbairns, 2001) la autora sostiene que Orwell ignora completamente el rol de la mujer y su individualidad. La trama de la novela es protagonizada por un hombre que está en conflicto con otros hombres. Si bien es cierto que Winston está enamorado de Julia, el papel que ella desarrolla es muy secundario y marginal. Lo que me lleva a interpretar que el propósito de Orwell era demostrar que las relaciones de poder y dominación en una sociedad residen exclusivamente en las manos de los hombres y no en las mujeres. 
y una camarada del partido. (Orwell, 1949, p. 204).

Diversos críticos de la obra de Orwell sostienen que su narrativa es un reflejo de su decepción por los Estados totalitarios, producto de la realidad vivida por este durante la guerra civil española y su perspectiva del régimen estalinista. Isaac Deutscher (1974) sostiene que la obra revela la desilusión hacia cualquier forma de socialismo a través de una valiosa y fiel interpretación de los horrores perpetrados durante las purgas estalinistas de 1936, cuyas repercusiones sufrió Cataluña. De la misma forma, Fernando Galván (2014), en el ensayo titulado Actualidad, polémica y consenso crítico sobre 1984 destaca que Orwell, en "Why do I write" manifiesta:

Los acontecimientos de 1936 y 1937 habían de hacerme ver claramente dónde estaba. Cada línea seria que he escrito desde 1936 lo ha sido, directa o indirectamente, contra el totalitarismo y a favor del socialismo democrático, tal como yo lo entiendo. Me parece una tontería, en un periodo como el nuestro, creer que puede uno evitar escribir sobre esos temas. (P. 23) ${ }^{4}$

Temas que incluyen la deformación de la historia, el uso de propaganda política, el rechazo a los sistemas totalitarios, la eliminación de la voluntad del individuo y su sometimiento al Estado, la censura a la prensa y el movimiento.

\section{B. 1Q84, de Haruki Murakami}

Al aproximarnos por primera vez a esta novela publicada en 2009, resulta curioso su título, pues es una referencia directa a 1984, de Orwell. La letra q y el número 9 son homófonos en japonés. De allí que el mundo creado por Murakami evoca la realidad creada por Orwell en la medida en que Tokio está plagado de sectas religiosas, corrupción, espionaje y personajes autoritarios.

En consecuencia debemos entender que Vanguardia, una comunidad religiosa, y Tokio, son sociedades con tintes totalitarios donde las personas están constreñidas a actuar conforme a los mandatos de la Little People y Fukada. ${ }^{5}$ Estas son separadas de su capacidad de autodeterminación. Por esto Aomame es consciente de que

aunque nos preocupemos por elegir el menú, hombre o lo que sea, quizá no estemos eligiendo en realidad. Tal vez todo está determinado desde un principio y solo aparentamos estar eligiendo. A veces pienso que el libre albedrío es solo una impresión subjetiva. (Murakami, 2011, p. 252, libro I).

4. Orwell, G. (1946). "Why I write”. En Collected Essays, Journalism and Letters, vol. I, p. 7.

5. Fukada es el fundador y líder de la comunidad religiosa con personalidad jurídica denominada Vanguardia. Este personaje recibe las instrucciones y mandatos de cómo se debe regir la comunidad de la Little People. Estas últimas son unas criaturas omniscientes que no pertenecen al mundo de lo terreno. 
Autores como Lorenzo Dávalos (2012) interpretan que la sociedad creada por Murakami, Vanguardia, es una comunidad totalitaria pues se caracteriza por ser inexpugnable, es una sociedad cuya estructura es hermética y hegemónica, semejante a un estado distópico. Compara a Vanguardia con un panóptico donde el líder tiene la capacidad de conocer de manera absoluta cuáles son las ideas, creencias, deseos, expectativas y pasiones de aquellos sobre los que ejerce su poder; su rol es el mismo de las estructuras de vigilancia de los sistemas autoritarios, el vigilar para infundir temor. Por lo tanto, para Dávalos (2012) parece que el poder dentro de la comunidad, Vanguardia, tiene su fundamento en la creencia y miedo que provoca en sus miembros el pensar que están siendo vigilados constantemente por el líder, aunque en la práctica no se hagan efectivas las sanciones.

\section{VALIDEZ FORMAL Y MATERIAL DE LAS NORMAS: NORBERTO BOBBIO Y SU OBRA TEORÍA GENERAL DEL DERECHO}

Frente al estudio de las reglas de conducta que rigen las comunidades totalitarias creadas en 1984 y 1Q84, es posible acudir a los postulados de Norberto Bobbio en su texto Teoría general del derecho. Aunque el jurista italiano Ferrajoli, seguidor y crítico de Bobbio sostiene que

tanto Kelsen como Bobbio, piensan, de hecho, que la validez de una norma equivale a su existencia, la cual depende únicamente de ser obra de una autoridad legitimada para ello, cuando actúa observando las formas y procedimientos establecidos (el "quién" y el “cómo" de su producción). (S.f., p. 37).

De allí que será válida aquella disposición dentro del sistema jurídico, independientemente de su eficacia o justicia, si la autoridad que la expidió era legítima y competente. Por tanto, se ignora su contenido moral y se prioriza su legalidad, defendiéndose un concepto positivista del derecho. Bobbio (1993) ilustra su posición al explicar que "el problema de la validez es el problema de la existencia de la regla en cuanto tal, independientemente del juicio de valor sobre su contenido de justicia" (p. 34).

Bobbio ofrece tres operaciones para decidir si una norma es válida y puede entenderse como una regla jurídica existente que pertenece a un determinado sistema. Primero, se debe determinar si la autoridad que la promulgó tenía el poder legislativo para expedir normas vinculantes dentro de ese ordenamiento jurídico. Segundo, acreditar que la norma está vigente al no haberse derogado por una ley posterior. Tercero, comprobar que no sea incompatible con otras normas del sistema, sobre todo con las normas de jerarquía superior (1993, p. 35). En caso tal que la norma cumpla con los tres presupuestos, gozará de validez formal y material. Esto significa que

una norma es formalmente válida cuando fue creada por el sujeto competente respetando los procedimientos establecidos pero solo es plenamente válida si satisface el cri- 
terio de validez material, es decir, si no está en conflicto con alguna otra norma del ordenamiento. (Salazar Ugarte, 2011, p. 2).

En el caso particular de 1984, se puede interpretar que la validez de las normas se ajusta a los criterios expuestos por Bobbio. Se tiene que la ley dentro de Oceanía es vinculante solamente si esta fue expedida por la autoridad legitimada para ello: el Gran Hermano. De allí que no es necesario evaluar el contenido moral de la norma para que esta sea legal e imperativa para los miembros del partido. Situación que se asemeja a lo expresado por Bobbio (2004) cuando sostiene que "el derecho, cualquiera que sea su contenido, tiene por sí un valor positivo y hay que prestar obediencia incondicionada a sus prescripciones" (p. 51).

Es por esto que, dentro de Oceanía, si un individuo actúa conforme a su propio criterio, desobedeciendo los postulados promulgados por el Gran Hermano, se entiende que su actuar es reprochable y debe ser sancionado, independientemente de que el sujeto en su fuero interno determine que es moral. Así pues, dentro de esta sociedad no es posible desobedecer el derecho cuando sus contenidos están en desacuerdo con lo que cada cual considera moralmente justificable; esto en razón de que las normas poseen validez formal y material y deben ser obedecidas so pena de ser sancionados.

En $1 Q 84$ el origen o forma de producir la ley dentro de Vanguardia obedece a un procedi- miento determinado que incluye dos actores: la Little People y el líder Fukada. Este último personaje es la autoridad legitimada para promulgar las normas que han de regir la comunidad religiosa, pues es el único que tiene la facultad de escuchar los mandatos que ordena la Little People. Fukada reafirma su autoridad para proferir la ley al decir, "lo que yo hago consiste simplemente en escuchar unas voces y trasmitírselas a la gente. Poseo algunas gracias divinas" (Murakami, 2011, p. 556, libro I). En consecuencia, se tiene que el procedimiento que se cursa para expedir una norma depende de que Fukada cumpla con el rol que le ha sido asignado, pues se menciona que los personajes han "entrado en este mundo porque necesariamente tenía que ser así, y ya que habéis entrado, se os han asignado vuestros respectivos papeles, os guste o no" (Murakami, 2011, p. 546, libro II). Es decir, siempre que Fukada dicte un mandato al escuchar y trasmitir (perciever) la voz de la Little Pleople, este será válido y obligatorio independientemente de su contenido moral, puesto que cumple con los criterios de validez formal y material ilustrados por Bobbio.

En este sentido Guillermo Lariguet (2014) sostiene la tesis de que en 1084 no existe un modelo de moralidad aplicable a la autoridad competente para expedir las normas. Es decir, que la moral guarda silencio frente a cómo evaluar los comportamientos de dichas autoridades. Para explicar esta idea Lariguet se remite a la escena en la cual Aomame conoce a Fukada (momentos antes de asesinarlo) y este le explica que él "no sabe si esto a lo que llaman 
la Little People es bueno o malo (...) trasciende la capacidad de definición y entendimiento" (Murakami, 2011, p. 561), ellos viven desde tiempos inmemoriales "antes de que el bien y el mal se encontrasen establecidos" (p. 555). Bajo la misma línea de reflexión, Aomame piensa que "Fukada había cometido actos que atentaban contra la moralidad" (p. 560). Sin embargo Fukada "no era una persona normal y corriente en diversos sentidos, esta falta de normalidad podía considerarse como algo que trascendía los criterios del bien y del mal" ( $p$. 562). Lo que significa que los personajes comprenden que existen comportamientos que no pueden ser evaluados moralmente porque los criterios de bien y mal no tienen aplicación sobre la autoridad que expide las normas dentro de la comunidad y por tanto su moral es indeterminada. Es claro cómo sus mandatos deben ser obedecidos sin evaluar su contenido, a la luz de un esquema de valores determinado, preservando para su validez únicamente su carácter formal y material.

Habiendo establecido que las normas dentro de Vanguardia y Oceanía resultan vinculantes en razón de tener validez formal y material, conviene estudiar la posible respuesta que ofrecen las novelas estudiadas a la siguiente pregunta: ¿Resulta justificable que un sujeto quebrante una norma válida aduciendo la protección de un bien jurídico superior? Es decir que cuando existan normas jurídicas creadas por la autoridad competente que entren en conflicto con lo que es justo y moral ¿está prohibido actuar legítimamente guiados por lo que individualmente consideramos correcto? Esta pregunta es apropiada en este estudio puesto que a este dilema ético jurídico se exponen los personajes principales creados por Orwell y Murakami. Respecto de 1984, los personajes se enfrentan a la necesidad de desobedecer los mandatos del partido en la búsqueda de su libertad individual. En 1Q84, Aomame decide convertirse en una asesina a sueldo, de hombres que abusan de sus esposas, para proteger los derechos de las mujeres.

El análisis literario resulta pertinente para resolver este problema jurídico porque es un método de reflexión que excede el marco de las disciplinas científicas. Muchos relatos literarios nos presentan diversos personajes y tramas que enfrentan al lector con las paradojas y problemas de un sistema con legalidad pero sin normas que ostenten la calidad de ser moralmente válidas; tal y como lo destacamos dentro del mundo de 1Q84 y 1984. El jurista está dominado por una lógica teórica que lo ata a una dogmática predeterminada, la cual lo amputa de métodos de interpretación diversos y de su creatividad. El discurso jurídico codifica la realidad a través de instituciones y procedimientos específicos y un sistema de obligaciones y derechos definidos. Por el contrario, la literatura carece de cualquier dimensión formal, ya que rechaza las convenciones establecidas permitiendo al autor crear y desbordar su imaginación. Es por ello que Aguiar e Silva (2001) sostiene que la literatura constituye una ventaja para los abogados, en la medida en que les ofrece una perspectiva de realidades diferentes a la tradicional, donde pueden imaginar y construir soluciones a las cuales no llegarían 
si se mantienen dentro de los límites del derecho. $^{6}$

\section{VALIDEZ Y JUSTICIA DE LAS NORMAS: FÓRMULA RADBRUCH}

Radbruch, el jurista alemán, se pregunta por el carácter obligatorio de una norma válidamente expedida pero injusta. Introduce la necesidad de contraponer el contenido moral del dictamen a su validez formal y material, para determinar cuál es la que debe ser obedecida. Los antecedentes al planteamiento de Radbruch remiten a los postulados de la tradición iusnaturalista clásica. San Agustín había manifestado: "Pues a mí me parece que no es ley la que es injusta" (citado por De Hipona, 1982, p. 192). En este mismo sentido Tomás de Aquino (1989) sostiene que "la ley positiva humana, si en algo está en desacuerdo con la ley natural, ya no es ley, sino corrupción de la ley" (p. 184). Vemos que estos autores reconocían que el efecto de crear una ley injusta es que puede ser desobedecida. Es decir, solo la ley justa y promulgada por la autoridad legítima tiene fuerza obligatoria, mientras que aquellas normas que son injus- tas "no obligan en el foro de la conciencia" (De Aquino, 1989, p. 184), se entienden como no vinculantes. Sobre la base de estas teorías clásicas se crea la fórmula Radbruch, la cual tiene como objetivo, "resolver las tensiones entre la seguridad jurídica y la justicia a las que da lugar un Derecho positivo legalmente promulgado pero de contenido injusto; o con mayor precisión, de contenido insoportablemente injusto, injustísimo" (Seoane, s. f., p. 765).

Radbruch sostiene que la ley positiva tiene tres valores, a saber: su capacidad de proporcionar seguridad jurídica, su adecuación a fin y la justicia. Y explica que la seguridad jurídica forma parte de la justicia, por eso declara:

Donde surge una pugna entre la seguridad jurídica y la justicia, entre una ley discutible en su contenido pero positiva, y un Derecho justo pero no vertido en forma de ley, existe en realidad un conflicto de la justicia consigo misma, un conflicto entre la justicia aparente y la real. (Citado en Seoane, s. f., p. 766).

Para solucionar este conflicto propone una fórmula, ${ }^{7}$ la cual dicta que el derecho manifiesta-

6. En este mismo sentido se puede reconocer la gran cualidad que posee la literatura de crear empatía entre el lector y los personajes, para que este se sienta emocionalmente identificado con la situación de otro. Por tanto, la literatura es capaz de formar panoramas morales que sirven como instancia crítica del derecho. Bajo esta idea se sitúan autores como Pergolesi (1927), quien reconoce el inmenso valor de la literatura para la sociología jurídica en razón a que pone en discusión problemas éticos.

7. La fórmula de Radbruch dice: “El conflicto entre la justicia y la seguridad jurídica debería poder solucionarse en el sentido de que el Derecho positivo asegurado por el estatuto y el poder tenga también preferencia cuando sea injusto e inadecuado en cuanto al contenido, a no ser que la contradicción entre la ley positiva y la justicia alcance una medida tan insoportable que la ley deba ceder como 'Derecho injusto' ante la justicia. Es imposible trazar una línea más nítida entre los casos de la injusticia legal y las leyes válidas a pesar de su contenido injusto; pero puede establecerse otra línea divisoria con total precisión: donde ni siquiera se pretende la justicia, donde la igualdad, que constituye el núcleo de la justicia, es negada conscientemente en el establecimiento del Derecho positivo, ahí la ley no es solo 'Derecho injusto', sino que más bien carece totalmente de naturaleza jurídica." (Seoane, s. f., p. 767) citando a Radbruch (1946). [Cursivas añadidas]. 
mente injusto no es derecho y, por tanto, no hay que obedecerlo. Es decir, prevalece el contenido moral sobre la validez formal y material del derecho. Alexy, dice Seoane (s. f.), ha propuesto una versión resumida de la fórmula Radbruch: “Las normas promulgadas conforme al ordenamiento y socialmente eficaces pierden su carácter jurídico o su validez jurídica cuando son extremadamente injustas" (p. 772).

Es preciso asociar esta idea expuesta por Radbruch a la razón por la cual los personajes de las novelas deciden no acatar las normas vigentes de su ordenamiento. En el caso de 1Q84, Aomame es una asesina a sueldo que se encarga de eliminar únicamente hombres que maltratan a las mujeres. Es contratada por la anciana de Azabu y su objetivo es erradicar la violencia de género. Esto es claro cuando la anciana le manifiesta a Aomame que ella "hizo lo que debía. Si ese hombre siguiera con vida, tarde o temprano acabaría haciéndoles pasar por lo mismo a otras mujeres" (Murakami, 2011, p. 281, libro I). A partir de ejemplos como este se evidencia que los personajes creados por el autor nipón quebrantan las normas en la búsqueda de proteger un bien jurídico superior. Para el caso de Aomame es el proteger a las mujeres de la violencia intrafamiliar.

Después de cometer algún asesinato Aomame reflexiona: "Yo he hecho lo correcto. Era necesario asesinar a ese hombre. No he cometido ningún error. Solo he infringido la ley" (Murakami, 2011, p. 612, libro II). Podemos apreciar que en el mundo de 1Q84 lo moral no siempre ha de ser lo legal. Por tanto, los personajes optan por desobedecer el derecho si para ellos resulta inmoral o injusto. En este caso, para Aomame, el respetar los postulados jurídicos significa permitir que la violencia de género se consolide como un hecho normal dentro de la sociedad. Por consiguiente, ella no encuentra vinculante la norma que le impide asesinar a aquellos hombres que son violentos, con la justificación de salvaguardar la libertad y protección de las mujeres. Ella conscientemente opta por desobedecer la norma jurídica porque considera que esta pierde validez al ser injusta, como lo expresa cuando dice, "si es que existe un juicio después de la muerte dios me juzgará. Pero no me da ningún miedo. Yo no he hecho nada malo" (Murakami, 2011, p. 281, libro I).

En 1984 la respuesta es la misma. Los personajes se enfrentan a una pugna entre las normas dictadas por Ingsoc y sus propios criterios de justicia. Winston y Julia optan por desobedecer aquellos dictámenes en la búsqueda por acceder a lo que consideran ser un bien jurídico superior: la libertad. Incluso, estos dos personajes llegan a jurar cometer todos los actos atroces que resulten necesarios para alcanzar su objetivo. Por esto es que al intentar ingresar a la Hermandad prometen:

En términos generales, ¿qué estáis dispuestos a hacer? -Todo aquello de que seamos capaces - dijo Winston. ¿Estáis dispuestos a cometer asesinatos? -Sí.-¿A cometer actos de sabotaje que pueden causar la muerte de centenares de personas inocentes? -Sí.¿Vender a vuestro país a las potencias extranjeras? -Sí. (Orwell, 1949, p. 233). 
Nuevamente se abstrae la fórmula Radbruch en la medida en que, para los personajes, existen comportamientos contrarios a la norma (como la rebeldía, los asesinatos, el sabotaje), que son justificados en razón de que son la vía para proteger bienes jurídicos superiores.

A partir del análisis realizado en esta sección podemos concluir que el derecho tiene como límite para la represión y control social, los juicios de valor internos de cada individuo. Es decir, que el derecho no se tendrá como vinculante por parte de las personas si este carece de criterios de justicia y moralidad al momento de ser promulgado. Ello significa que si la norma es injusta no es posible utilizarla como un método de control social ya que los sujetos no la van a obedecer, pues se dejarán guiar por lo que individualmente consideran correcto en determinada situación, en aras de salvaguardar un bien jurídico superior.

\section{PROCESO JUDICIAL, PENA Y CRIMINAL}

\section{A. Proceso judicial y verdad}

En Oceanía el objetivo del proceso judicial no es encontrar la verdad, sino que este tiene un contenido sancionador. De allí que no se pretende establecer una versión objetiva de la comisión de unos hechos ilícitos para llevar a un juez a un estado de certeza. En consecuencia, dentro del proceso hay ausencia de pruebas, no existen documentos ${ }^{8}$ ya que todos han sido alterados. El proceso lo que busca es torturar al implicado, quien está consiente de este mecanismo, ${ }^{9}$ por esto Julia reconoce: "Si confieso te fusilarán. Si me niego a confesar te fusilarán también" (Orwell, 1949, p. 227).

Es así como el proceso judicial no es una instancia anterior a la pena sino la pena misma. Esto se hace evidente al analizar la naturaleza jurídica del crimental. "Las consecuencias de cada acto van incluidas en el acto mismo -el crimental (el crimen de la mente) no implica la muerte, el crimental es la muerte misma" (Orwell, 1949, p. 92). Se denota que el proceso judicial y la norma penal siempre buscan alcanzar la protección del bien jurídico mayor, la estabilidad y la seguridad por encima de la integridad física y moral del implicado.

En contraste, dentro del mundo de 1084 existe el Estado que gobierna Tokio, sin embargo esta institución de gobierno no puede llevar a cabo procesos judiciales efectivos dentro de Vanguardia, ya que esta se rebela como una

8. "Y ya apenas conocemos nada de la Revolución y mucho menos de los años anteriores a ella. Todos los documentos han sido destruidos o falsificados, todos los libros han sido otra vez escritos, los cuadros vueltos a pintar, las estatuas, las calles y los edificios tienen nuevos nombres y todas las fechas han sido alteradas. Ese proceso continúa día tras día y minuto tras minuto. La Historia se ha parado en seco. No existe más que un interminable presente en el cual el Partido lleva siempre razón. Naturalmente, yo sé que el pasado está falsificado, pero nunca podría probarlo aunque se trate de falsificaciones realizadas por mí." (Orwell, 1949, p. 89).

9. “Todos tenían que confesar, como cuestión de mero trámite... tenían que confesar todo los delitos verdaderos o imaginarios de que los acusaran" (Orwell, 1949, p. 297). 
comunidad impenetrable para el derecho estatal. ${ }^{10}$ Esto se hace evidente cuando personajes como Ayumi (policía) le confía a Aomame que existen muchos obstáculos para investigar a aquella comunidad: "Vanguardia se convirtió en comunidad religiosa con personalidad jurídica (...) así es muy difícil que la policía pueda entrar a investigar porque amenazaría la libertad de credo garantizada en la constitución. - es una organización religiosa sumamente hermética" (Murakami, 2011, p. 197, libro I). De allí se puede extraer que es una institución aislada de la fuerza investigativa y policiva del Estado y, por tanto, tiene una organización y estructura independientes. De allí que se puede establecer que no existe la consecución de un proceso judicial satisfactorio.

\section{B. Fin de la pena y criminal}

Es necesario referirnos a la teoría sobre los fines de la pena, formulada por distintos filósofos representativos del idealismo alemán. Kant expone la teoría de la retribución, según la cual la pena debe ser proporcional a la culpabilidad. Según el planeamiento kantiano de la retribución moral,

el derecho penal es el derecho que tiene el soberano, con respecto a aquél que le está sometido, de imponerle una pena por su delito. El único fundamento de la pena, para Kant, es la retribución a la culpabilidad del sujeto. La aplicación de la pena es, para él, una necesidad ética, una exigencia de la justicia. Por tanto, los posibles efectos preventivos que se pretendan atribuir a la pena son artificiales y ajenos a su esencia. (Duran Migliardi, 2011, pp. 123-144).

Kant basa su teoría en la idea de libertad que tiene cada ser humano de escoger si ha de cometer o no un delito. De ahí decide fundamentar la pena en la retribución de la culpabilidad del delincuente, puesto que el derecho penal sería considerado como "la reacción de frente al uso inconveniente de la libertad realizado por un hombre que, utilizando su libre albedrío, ha optado por el mal pudiendo haber realizado el bien" (Duran Migliardi, 2011).

Al contrastar la teoría sobre los fines de la pena formulada por Kant con el régimen imperante dentro de Ingsoc se evidencia que esta le es aplicable. Dentro de Ingsoc la rebelión y la conspiración son infracciones altamente reprochables, razón por la cual conducen a penas más graves. La idea detrás de esta teoría es la expiación de la culpa, entendida como el daño y sufrimiento que debe padecer el delincuente, en este caso Winston y Julia, debido al daño

10. Lariguet indica que los personajes que despliegan sus acciones dentro de la obra del autor nipón se mueven por "fuera del espacio de la ley" (2014, p. 121). Es decir, que Fukada no es investigado legalmente por un juez. Lo que evidencia que Vanguardia es ajena a toda forma de control e intervención estatal. De allí que Aomame deba tomar justicia por mano propia. La reflexión que pretende el autor crítico de Murakami es que, a pesar de que exista un estado cuyo poder sancionatorio es limitado no existen sujetos con un poder tal como para evitar que sus actos queden impunes. Idea que se asocia con el “tiranicidio" propuesto por la filosofía política clásica. 
o sufrimiento que ha producido con su actuar al partido político. Tal como lo expone Taylor cuando dice que "la pena tiene por finalidad disminuir la incidencia del delito y ha de ser proporcional al grado en que el hecho viole la propiedad, el bienestar individual y el del Estado" (2007, p. 32).

Vemos entonces que el derecho en 1984 es una construcción social: quien desobedece lo pactado debe ser "reparado" ${ }^{11}$ La norma legítimamente creada construye la realidad moral y física. Si el Gran Hermano me dice que dos más dos son cinco así es so pena de ser purificado en el Room 101. Esto lo comprueban los protagonistas del relato quienes se dan cuenta que estaban en un error cuando pensaban que "pueden forzarte a decir cualquier cosa, pero no hay manera de que te lo hagan creer. Dentro de ti no pueden entrar nunca... el contenido de tu corazón es inexpugnable" (Orwell, 1949 , p. 228), pues la capacidad coercitiva del derecho puede cambiar hasta los sentimientos más íntimos, no tiene un límite para su facultad sancionadora.

Aquí es preciso resaltar la idea expuesta por Santiago (2003) acerca de que en la novela de Orwell el crimental es el símbolo de un derecho penal sin tipicidad. Por esto se menciona que "sus actos no están regulados por ninguna ley ni por un código de conducta claramente formulado. En Oceanía no existen leyes. Los pensamientos o actos que una vez descubiertos acarrean la muerte no están prohibidos expresamente" (Orwell, 1949, p. 268). Santiago sostiene que la sociedad de 1984 sufre de un alto nivel de coerción que se perpetúa a través de la violencia. Lo interesante de esta idea es que puede interpretar que existe un derecho penal sin tipicidad ya que los crímenes (como el crimental) son de interpretación arbitraria.

Del argumento anterior se desprende el análisis de que el derecho penal dentro de Oceanía es uno de autor. En los términos de Roxin hay derecho penal de autor cuando:

La pena se vincule a la personalidad del autor y sea su asocialidad y el grado de la misma lo que decida sobre la sanción. Lo que hace culpable aquí al autor no es ya que haya cometido un hecho, sino que solo el que el autor sea tal que se convierte en objeto de la censura legal. (1999, p. 176).

Al aplicar este concepto al análisis de la obra encontramos que Ingsoc acusa y sanciona constantemente a Jones, Aaronson y Rutherford por haber sido los líderes originales de la revolución, es decir, en razón de sus calidades personales.

Dentro de Oceanía el derecho penal también tiene como fundamento el ser un derecho que sanciona la peligrosidad, no la comisión de

11. Dentro de Oceanía el derecho revela su faceta coercitiva, el propósito de la pena es expiar y reeducar. Quien simboliza esta postura es O'Brien, quien funge para Winston como su atormentador, su protector, su inquisidor -“estás bajo mi custodia. Te salvaré, te haré perfecto... Estás trastornado mentalmente (p. 139) te hemos traído para curarte y volverte cuerdo” (p. 142). 
actos sino la potencialidad de ser cometidos. Esta idea fue expuesta por Raffaele Garofalo $(2012)^{12}$, autor que sostiene que la responsabilidad penal se funda en la peligrosidad, que es el potencial quehacer u omisión de una persona dados sus antecedentes familiares, genéticos, profesionales. Este es el sustento para que el criminal sea sancionado. ${ }^{13}$ Esto último se evidencia de manera clara en ejemplos ${ }^{14}$ como “¿no me matarán, verdad? No le matan a uno cuando no ha hecho nada concreto y solo es culpable de haber tenido pensamientos que no pudo evitar. Sé que le juzgarán a uno con todas las garantías" (Orwell, 1949, p. 290).

Aquí es preciso preguntarnos, ¿quién ha de ser catalogado como criminal dentro de esta sociedad? Para establecer su respuesta podemos remitirnos a la teoría clásica de la criminología. Uno de sus principales exponentes, Tim Newburn (2007), define el crimen como una acción voluntaria, producto de la mente racional que calcula qué tanto placer va a obtener y a qué costo. Es por esto que el Estado debe crear un derecho penal eficiente que haga pensar al criminal que la pena impuesta será inminente, haciendo más costoso que beneficioso el delito.

La base de los postulados de la escuela clásica de criminología se encuentra en la teoría del contrato social. Los hombres y las mujeres se unieron libremente en sociedad y establecieron acuerdos que garantizaban el orden y la convivencia, los cuales, de ser incumplidos, presuponen la imposición de una pena cuyo propósito es asegurar la persistencia de la sociedad. Es el Estado, en virtud del pacto social, quien tiene el derecho de castigar aquellas conductas que resulten perjudiciales para la colectividad, y de recompensar las que contribuyen a su mantenimiento. La teoría clásica explica que el actuar en contra del contrato social es una actitud irracional ya que no solo atenta contra la sociedad, sino que también significa atentar contra sí mismo en la medida en que ha aceptado el pacto social para beneficiarse (Newburn, 2007). Por esto se dice que

12. Garofalo sostiene que los delincuentes son diferentes al resto de los miembros de la sociedad, poseen una "anomalía moral" la cual es congénita. Es decir, que los rasgos físicos y las enfermedades heredadas por sus familiares, así como el contexto social en el cual creció y desarrolla su proyecto de vida, son los factores determinantes para el desarrollo de una conducta delictual. Él ilustra su teoría citando a Lombroso, los caracteres físicos y morales que se observan en los delincuentes son tales que puede darse el tipo antropológico del delincuente, que se describe de la siguiente forma: el índice del cráneo es conforme al grupo étnico pero más exagerado, las asimetrías craneales y faciales son frecuentes, colocación anómala de las orejas (...). (Garofalo, 1912, p. 71). Asimismo explica que "existen anomalías patológicas de todo género en la clase criminal (...) con frecuencia se encuentra el alcoholismo o la epilepsia en los padres del delincuente lo cual explica la neurosis y locura en los descendientes" (p. 97).

13. "La corriente afirma que hay hombres que nacen con predisposición hacia su futura manera de comportamiento, de acuerdo con sus características biológicas, antropológicas y psicológicas”. (González y González, 2007, p. 167). De manera que si se encuentran ciertas características físicas y emocionales dentro de un sujeto se tiene como peligroso pues se prevé que cometería delitos. El derecho penal es el mecanismo para reducir ese peligro.

14. Orwell (1949): “A los ojos del partido no había distinción alguna entre los pensamientos y los actos” (p. 300). "Al partido no le interesan los actos realizados; nos importa solo el pensamiento" (p. 144). 
"todo comportamiento ilegal producido en una sociedad en la que se ha celebrado un contrato social es irracional, el comportamiento de hombres que por sus defectos personales no pueden celebrar contratos" (Taylor, 2007). Sin embargo este comportamiento irracional ocurre cuando, dadas las oportunidades, cualquier persona considera que el hecho le genera más beneficios que costos. De allí que le corresponde al Estado generar los incentivos adecuados y construir un sistema penal eficiente para evitar el crimen.

Bajo esta teoría Winston y Julia deben ser catalogados como criminales ya que deciden libremente sostener una relación y vincularse a la Hermandad, a la vez que planean objetivamente encuentros y escondites, sabiendo que su actuar está prohibido y las consecuencias que su comportamiento acarrea. ${ }^{15} \mathrm{Su}$ análisis radica en que están dispuestos a morir (saben que van a morir) pero asumen ese costo para poder estar juntos. ${ }^{16}$
En los términos de Newburn (2007) podría interpretarse que su actuar es irracional pues actúan en contra del contrato social, es decir, infringen las leyes de Ingsoc. Su rebeldía no solo afecta a la sociedad de Oceanía sino que tiene efectos negativos sobre sí mismos. El partido decide entonces crear un sistema de penas lo suficientemente fuerte como para erradicar el deseo de delinquir. ${ }^{17}$ Los personajes, al ser sometidos a los interrogatorios y torturas, están en la capacidad de decidir autónomamente que les resulta más costoso verse sometidos a estos malos tratos que abstenerse de realizar crímenes.

Encontramos que el derecho halla un nuevo límite para lograr mantener el control social. Este es la conciencia humana y los deseos individuales. Es decir, el derecho deja de ser imperativo porque cada persona tiene una escala de valores individual, la cual utiliza como referente para hacer el análisis costo-beneficio antes de pensar en delinquir. Ello significa que

15. “Desde luego, no había telepantallas, pero siempre quedaba el peligro de los micrófonos ocultos que recogían vuestra voz y la reconocían. Además, no era fácil viajar individualmente sin llamar la atención. Para distancias de menos de cien kilómetros no se exigía visar los pasaportes, pero a veces vigilaban patrullas alrededor de la estaciones de ferrocarril y examinaban los documentos de todo miembro del Partido al que encontraran y le hacían difíciles preguntas." (Orwell, 1949, p. 67).

16. "Ya he pensado en todo eso. Lo que tú hagas, eso haré yo. Y no te desanimes tanto. Yo sé arreglármelas para seguir viviendo. -Quizás podamos seguir juntos otros seis meses, un año... no se sabe. Pero al final es seguro que tendremos que separarnos. ¿Te das cuenta de lo solos que nos encontraremos? Cuando nos hayan cogido, no habrá nada, lo que se dice nada, que podamos hacer el uno por el otro. Si confieso, te fusilarán, y si me niego a confesar, te fusilarán también. Nada de lo que yo pueda hacer o decir, o dejar de decir y hacer, serviría para aplazar tu muerte ni cinco minutos. Ninguno de nosotros dos sabrá siquiera si el otro vive o ha muerto. Sería inútil intentar nada. Lo único importante es que no nos traicionemos, aunque por ello no iban a variar las cosas." (Orwell, 1949, p. 96).

17. Se crea el Ministerio del Amor, encargado de mantener la ley y el orden. "El Ministerio del Amor era terrorífico. No tenía ventanas en absoluto. Era imposible entrar allí a no ser por un asunto oficial y en ese caso había que pasar por un laberinto de caminos rodeados de alambre espinoso, puertas de acero y ocultos nidos de ametralladoras. Incluso las calles que conducían a sus salidas extremas, estaban muy vigiladas por guardias, con caras de gorila y uniformes negros, armados con porras" (Orwell, 1949, p. 5). Asimismo se crea la habitación 101, "Me preguntaste una vez qué había en la habitación 101. Te dije que ya lo sabías. Todos lo saben. Lo que hay en la habitación 101 es lo peor del mundo” (p. 163). 
el derecho no logra prever todos aquellos placeres y valores que pesan más que una sanción, pues estos varían de persona a persona. Para un individuo un valor o placer determinado puede justificar quebrantar la ley, mientras que para otro sujeto en la misma situación no le ha de reportar el placer suficiente para exponerse a la sanción que acarrearía sus acciones. En consecuencia el derecho penal debe ser atípico, pues no está en la capacidad de prever el infinito universo de acciones y valores que son placenteros de persona a persona, para sancionarlos.

Asimismo es evidente que el derecho está limitado en la medida en que requiere que el delito esté consolidado para poder intervenir y reeducar al sujeto. Es decir, el derecho necesita que haya descontrol o una anomalía social para poder desplegar su capacidad sancionadora. Creando una paradoja, no es un mecanismo idóneo para controlar la sociedad pues para intervenir necesita descontrol.

El fin de la pena en $1 Q 84$ tiene un tratamiento diferente. Dentro de Vanguardia el fin de la pena no es expiar sino prevenir o evitar que se cometan actuaciones contrarias a los principios y reglas de la comunidad. Esta teoría se asocia con la prevención de delitos futuros de Feuerbach (1989) donde el sujeto, antes de delinquir, realiza un análisis costo-beneficio entre el costo de la pena a ser impuesta y el beneficio de cometer la conducta. Así es como Feuerbach formula la teoría de la prevención general de los delitos donde sostiene que "la pena debe ser un factor de inhibición psicológi- ca para que los ciudadanos no se decidan a cometer un hecho delictivo" (García Cavero, s. f., p. 6). Se debe entender que su función se predica sobre la totalidad de los individuos integrantes de una comunidad (Feuerbach, 1989, $\S 13)$. Esto último es distinto a la prevención especial que implica el intentar que un ciudadano en particular, que ya ha delinquido, vuelva a cometer los mismos actos sancionables.

Dentro del mundo creado por Murakami (2011), la pena o sanción no tiene una incidencia directa sobre el cuerpo físico del implicado, a diferencia de lo que ocurre en la novela de Orwell. La Little People es la encargada de imponer estos castigos, los cuales tienen el propósito de advertir a las personas acerca de que deben evitar cometer ilícitos. Su rol es preventivo.

\begin{abstract}
¿No pueden hacernos nada, pero en cambio pueden hacerle algo a la gente que nos rodea? (...) a lo mejor la Little People ha utilizado su poder contra mi novia para prevenirme. (...) Lo que la Little People puede hacer tiene unos límites. (Murakami, 2011, p. 576, libro II).
\end{abstract}

Concepto que nuevamente se repite después del asesinato de Ayumi, la mejor amiga de Aomame, cuando se menciona: "Ellos no pueden atacarme, así que se dirigirán a los puntos débiles que hay a mi alrededor. Como advertencia" (Murakami, 2011, p. 563, libro II). En estos ejemplos vemos expuesta la teoría de la prevención general. Las penas impuestas por la Little People tienen efectos sobre la comunidad 
en general y están destinadas a que los sujetos se abstengan de cometer actos reprochables.

Sobre este punto, la reflexión respecto al límite del derecho como mecanismo de control social es que este solo ejerce un control aparente sobre la comunidad. Está dirigido a la comunidad en general pero no se especializa en el delincuente en particular. Este último puede seguir delinquiendo ya que las consecuencias no las sufre él directamente. Como prueba de ello esta Aomame, quien se abstrae de la capacidad sancionadora de la Little People y se esconde en un edificio durante varios meses, siéndole imposible a las criaturas encontrarla y castigarla.

\section{ESTRUCTURALISMO SOCIAL: WEBER Y EL MODELO TRIDIMENSIONAL DE ESTRATIFICACIÓN}

Ingsoc se caracteriza por su fuerte separación y división social. Esta estructura contiene dos elementos: un patrón de distribución del trabajo y una marcada estratificación social. Respecto del primero es preciso decir que a los miembros del partido se les asigna un oficio específico en la sociedad, el cual determina su valía dentro del sistema. Es decir, dependiendo del rol asignado, un miembro ha de resultar indispensable o intrascendental. Quien no desarrolla una función importante para el partido no puede ser considerado un camarada útil.
Es por esto que los proles no están vinculados como miembros del Partido Exterior.

La distribución del trabajo es tal que evita que se creen relaciones personales entre los individuos, toda vez que asegura que la comunicación sea coartada y por tanto no haya sociabilidad. A modo de ejemplo, podemos leer: "Winston no conocía apenas a Tillotson, ni tenía idea de la clase de trabajo que le había sido encomendado. Entre sí no hablaban de sus funciones" (Orwell, 1949, p. 106). Al lado de este efecto podemos constatar que la distribución del trabajo se hace con base en las características de las personas y no de forma fortuita. Es decir, al asignar un trabajo se mira la idoneidad del sujeto para llevarlo a cabo. Es por esto que

en la Pornosec, excepto el jefe, no había más que chicas. Dominaba la teoría de que los hombres, por ser menos capaces que las mujeres de dominar su instinto sexual, se hallaban en mayor peligro de ser corrompidos por las suciedades que pasaban por sus manos. -Ni siquiera permiten trabajar allí a las mujeres casadas -añadió-. Se supone que las chicas solteras son siempre muy puras. (Orwell, 1949, p. 192).

Respecto del segundo elemento, la estratificación social, ${ }^{18}$ es adecuado identificar en la novela 1984 algunos aspectos de las principales

18. “En el vértice de la pirámide está el Gran Hermano (...) detrás se halla el Partido Interior del cual forman parte 6 millones de personas, el $6 \%$ de la población -es el cerebro-después el Partido Exterior -las manos-. Abajo están los proles (85\% de la población). Al final están las masas de esclavos procedentes de tierras ecuatoriales". (Orwell, 1949, p. 266). 
teorías sobre la estructura social y la distribución del poder. Por ello retomaremos la teoría de clases de Weber, desarrollada en la obra Economía y sociedad, para analizar si sus principios son los mismos que rigen la sociedad de Oceanía en 1984.

Weber propone un modelo tridimensional de estratificación como forma en la cual se distribuye el poder en las sociedades. Revela que "los fenómenos de la distribución del poder dentro de una comunidad están representados por las 'clases', los “estamentos' y los 'partidos'” (Weber, 1964, § 6, párr. 2). La división de clases sociales, entonces, no es la única forma en la cual está estructurada una comunidad. Para Weber existen tres principios de estratificación: la separación de orden económico (representada en clases), de orden social (representada en estamentos) y política (representada en partidos). El poder es el elemento que constituye las jerarquías de las tres dimensiones. Poder es, entonces, según Weber (1964), “la probabilidad que tiene un hombre o una agrupación de hombres, de imponer su propia voluntad en una acción comunitaria, inclusive contra la oposición de los demás miembros" (p. 682).

El primer principio de estratificación social hace alusión únicamente a la capacidad adquisitiva de las personas. ${ }^{19}$ Lo que determina la clase social a la cual se pertenece es la cantidad de bienes que componen su patrimonio y la forma en la cual pueden ser comercializados, adquiriendo de estos un incremento en su valor. En la sociedad de Oceanía, en 1984, existen clases sociales basadas en la desigualdad de bienes que poseen las personas. Es por esto que los miembros del Partido Interior están ubicados en la clase alta, ya que gozan de los mayores privilegios, los mejores predios, prendas valiosas y alimentos caros y escasos. Esto último se evidencia en un aparte de la novela que dice:

En muy raras ocasiones se podía penetrar en las residencias del Partido Interior, ni siquiera en el barrio donde tenían sus domicilios. La atmósfera del inmenso bloque de casas, la riqueza de amplitud de todo lo que allí había, los olores -tan poco familiares- a buena comida y a excelente tabaco, los ascensores silenciosos e increíblemente rápidos, los criados con chaqueta blanca apresurándose de un lado a otro. (Orwell, 1949, p. 97).

Es evidente cómo existe una desigualdad pronunciada entre las riquezas que poseen los miembros del Partido Interior frente a las condiciones de los miembros del Partido Exterior, que no pueden acceder sino a raciones determinadas de alimentos, o a los proles que apenas tienen qué comer. De allí que es posible considerar que en Oceanía existen clases basadas en el primer principio de estratificación social de Weber. Como se evidencia en la

19. "Hablamos de una 'clase' cuando: 1) es común a cierto número de hombres un componente causal específico de sus probabilidades de existencia, en tanto que, 2) tal componente esté representado exclusivamente por intereses lucrativos y de posesión de bienes, 3) en las condiciones determinadas por el mercado." (Weber, 1964, § 6, párr. 3). [Cursiva en el original]. 
calidad de vida de los miembros externos del partido por oposición a los miembros internos.

Winston no recordaba nada que fuera muy diferente. En todo el tiempo a que alcanzaba su memoria, nunca hubo bastante comida, nunca se podían llevar calcetines ni ropa interior sin agujeros, los muebles habían estado siempre desvencijados, en las habitaciones había faltado calefacción, los metros iban horriblemente atestados, las casas se deshacían a pedazos, el pan era negro, el té imposible de encontrar, el café sabía a cualquier cosa, escaseaban los cigarrillos y nada había barato y abundante a no ser la ginebra sintética. (Orwell, 1949, p. 36).

El segundo principio hace alusión a los estamentos, ${ }^{20}$ los cuales están compuestos por el prestigio y el honor de los individuos. Weber expone que se hace parte de un estamento a través de una sucesión o un intercambio personal. Es claro que en Oceanía también existen estamentos, pero estos corresponden a las mismas clases ya que la capacidad adquisitiva en 1984 va a determinar el prestigio de una persona dentro de la misma sociedad. Un ejemplo de ello son las alusiones que se hacen a los proles: "Los proles no son seres humanos" (Orwell, 1949, p.
38), su olor era como "aspirar el insoportable olor de la cocina del sótano, un olor a insectos, ropa sucia y perfume baratísimo (...) Solamente los proles se perfumaban, y ese olor evocaba en la mente, de un modo inevitable, la fornicación" (Orwell, 1949, p. 38). Es evidente que son juzgados y estratificados a partir de sus hábitos y costumbres, las cuales no se tienen como honorables y prestigiosas.

Si bien existen clases y estamentos dentro de Oceanía, el último principio expuesto por Weber no se ve reflejado dentro de esta sociedad. Este principio de estratificación es el del poder político representado en partidos. ${ }^{21}$ El propósito de pertenecer a uno de estos partidos es el de adquirir poder político. En Oceanía solo existe un partido político cuya única finalidad es conseguir poder para el jefe, como un patronazgo. Por tanto las personas no se ven divididas en razón de sus preferencias políticas sino que existe un solo estrato: el mismo partido político. El fervor hacia este partido se denota en las referencias que hacen los personajes de 1984 sobre el Gran Hermano. Estos evocan sentimientos tan profundos como "amaba al Gran Hermano" (Orwell, 1949, p. 355) y mencionan: "El Gran Hermano: infalible y todo poderoso. Todo triunfo, todo descubrimiento científico, toda sabidu-

20. “Llamaremos situación estamental a todo componente típico del destino vital humano condicionado por una estimación social específica - positiva o negativa- del honor adscrito a alguna cualidad común a muchas personas. (...) En cuanto a su contenido, el honor correspondiente al estamento encuentra normalmente su expresión ante todo en la exigencia de un modo de vida determinado a todo el que quiera pertenecer a su círculo." (Weber, 1964, p. 687).

21. “Los partidos se mueven primariamente dentro de la esfera del 'poder'. Su acción está encaminada al 'poder' social, es decir, tiende a ejercer una influencia sobre una acción comunitaria, cualquiera que sea su contenido". "Sus medios para alcanzar el poder pueden ser muy diversos, desde el empleo de la simple violencia hasta la propaganda y el sufragio por procedimientos rudos o delicados: dinero, influencia social, poder de la palabra, sugestión y grosero engaño." (Weber, 1964, p. 693). 
ría, toda felicidad, procede de su inspiración y poder" (Orwell, 1949, p. 265).

Tras haber analizado la teoría estructuralista de Weber, conviene destacar que el autor determina que el poder político dentro de una comunidad es legítimo siempre y cuando haya sido obtenido por ser carismático, tradicional o racional-legal. El poder del Gran Hermano dentro de la novela encuentra su legitimidad en su carisma. ${ }^{22}$ Esto se evidencia porque existe un gran despliegue de publicidad y carteles que cubren la ciudad con el rostro del líder elevándolo al nivel de un Dios.

Por su parte, al aplicar el modelo de estratificación social de Weber a la novela de Murakami es posible concluir lo siguiente. Dentro de la sociedad que se desarrolla en Tokio, hay clases que se ajustan al primer principio de Weber. Estas se diferencian por el dinero y las riquezas materiales. Como ejemplo de ello podemos referir la fortuna que identifica a la anciana de Azabu, quien reside en "una antigua mansión de estilo occidental en el barrio la Villa de los Sauces" (Murakami, 2011, p. 109), posee servidumbre y seguridad privada especializada. Así mismo, ella disfruta de pasatiempos costosos como el coleccionar y criar exóticas mariposas dentro de su invernadero.
Respecto del segundo principio es posible decir que existen estamentos que corresponden a las mismas clases al igual que en 1984. Esto se evidencia porque hay personajes que sostienen un estilo de vida mucho más modesto y realizan actividades que no son equiparables a las de la gente pudiente, como la anciana de Azabu. Como ejemplo está la infancia de Aomame y Tengo, quienes compartían la misma actividad dominical.

La niña daba vueltas con su madre, predicando. La madre llevaba en una mano una bolsa de tela llena de ejemplares de Ante el diluvio. Tengo se la había cruzado varias veces cuando había acompañado a su padre en las rutas de cobro de la tarifa de recepción de la NHK. (Murakami, 2011, p. 201).

Es por ello que se puede concluir que existe una estratificación por estamentos dentro de 1Q84, pues el prestigio determina la posición social. Al lado de esto está la discriminación de la cual es víctima Tengo por el trabajo modesto de su padre: “En tercero de primaria empezaron a llamarlo por el mote de NHK, en un círculo formado por hijos de oficinistas de clase media, él tenía que ser de una clase diferente" (Murakami, 2011, p. 124). ${ }^{23}$

22. “Existen tres tipos puros de dominación legítima. El fundamento primario de su legitimidad puede ser: De carácter carismático: que descansa en la entrega extracotidiana a la santidad, heroísmo o ejemplaridad de una persona y a las ordenaciones por ella creadas o reveladas (Ilamada) (autoridad carismática). (Weber, 1964. Primera parte, Los tipos de dominación).

23. Otros ejemplos de la estratificación social sobre la base de los estamentos dentro de 1 Q84 son: "Es una sociedad jerárquica más ostensiva que el mundo terrenal, se distingue perfectamente quiénes son los dirigentes y quiénes son los dirigidos. Si no se posee un expediente académico brillante y un talento profesional, no se puede formar parte de la dirección (...) el resto dona dinero, se dedica a labores de campo y medita. Son igual que un rebaño de ovejas." (Murakami, 2011, p. 374). 
A diferencia de 1984 , dentro de la novela del autor nipón sí existe una división social en partidos políticos, como se deduce de la presencia de diferentes corrientes de izquierda que están en pugna con el gobierno estatal y dan origen a Vanguardia. Esta se constituyó a través de un

proceso de la facción radical durante 1970, donde se creó una actividad política en la zona urbana alrededor de un campus universitario la cual se retiró a predios rurales para conformar una agrupación comunal. Este grupo se escindió en dos facciones. Una radical a favor de la lucha armada, un movimiento revolucionario de guerrillas guiado por los dictados del marxismo y una facción comunal pacífica pero que rechazaba el espíritu del capitalismo. (Murakami, 2011, p. 341).

A partir de este ejemplo es claro que dentro de la sociedad de Tokio, donde se desarrolla el argumento de la novela, los individuos también están estratificados por partidos según sus creencias, sean estas revolucionarias 0 pacíficas, cumpliéndose en 1Q84 con los tres principios que describe Weber en su teoría tridimensional de estratificación y división social.

El poder dentro de Vanguardia obedece a un tipo distinto de legitimación, según la teoría de Weber. Resulta posible asimilar la figura de la Little People de 1084 al Gran Hermano de 1984 como símbolo de unidad social, pues los personajes revelan que "el término del Gran Hermano se convirtió en un ícono social (...) en el mundo actual el gran hermano ya no pinta nada. En su lugar ha aparecido la Little People" (Murakami, 2011, p. 304, libro I). La figura de la Little People se revela como la adecuación que hace Murakami del Gran Hermano a una sociedad más contemporánea. Sin embargo, la legitimidad de la Little People y Fukada no reside en el mismo pilar conceptual de Weber cuando describe las autoridades carismáticas. Las criaturas y Fukada ostentan su legitimidad a partir del fundamento tradicionalista. Para Weber la autoridad tradicional es aquella que "descansa en la creencia cotidiana en la santidad de las tradiciones que rigieron desde lejanos tiempos y en la legitimidad de los señalados por esa tradición para ejercer la autoridad" (Weber, 1964, 172). Vanguardia tiene como eje central de sus costumbres, desde el momento en que fue creada, el culto hacia la voz de la Little People, la cual ha de regir la comunidad. Es por esto que se obedecen las costumbres adquiridas para lograr escucharla, como son los rituales con las daughters y Fukada.

Sin embargo, autores como Dávalos (2012), en su texto Metáforas del poder y del amor en 1 Q84 difieren de este análisis e interpretan que la legitimidad de Fukada como líder de Vanguardia radica en que detenta un poder carismático. Este mismo autor manifiesta que a pesar de que los personajes de la historia son conscientes de que los actos cometidos por su líder son incorrectos, este debe ser obedecido puesto que él inspira una infinita confianza en razón de sus poderes sobrenaturales. Es así como Aomame, al hablar con el líder, reconoce que este ha cometido actos reprochables cuya responsabilidad él mismo reconoce e incluso 
se arrepiente. Por eso ella manifiesta: "Seguramente, usted (Fukada) también es un ser muy capaz y superior, estoy segura de que debe haber un mundo en el cual no había necesidad de que yo lo mate", a lo cual el líder responde: "Ese mundo ya no existe" (Murakami, 2011, p. 560). De esta escena Dávalos interpreta que el carisma del líder le permite distraer la atención de los individuos para que estos no juzguen sus actos como morales o inmorales, si no que los acepten como mandatos y preceptos legítimos.

En un sentido similar Lariguet (2014), en su ensayo Más allá del bien y del mal: un análisis de la obra de Haruki Murakami, sostiene que Fukada es una autoridad carismática. Dentro de su argumentación equipara a Fukada con un superhéroe con cualidades especiales. ${ }^{24}$ Según este autor lo que la comunidad adopta como moral y decide obedecer son los mismos valores que siguen y adoptan de los señores o líderes. Como ejemplo de esto sostiene que en Vanguardia los individuos profesan ciegamente los mandatos de su líder, aun sin conocerlo. Al lado de este argumento, menciona que las actuaciones de cada individuo dentro de Vanguardia no han de ser evaluadas a la luz de la misma moralidad. Esto ocurre porque su idea de moral es asunto de jerarquías. Por esta razón, el líder es tratado con una moral diferente a la de los habitantes. En 1Q84 esto se evidencia en la medida en que, a pesar de los actos atroces cometidos por Fukada (violaciones a menores), sus actos son aceptados y justificados, mientras que los errores cometidos por otros miembros de la comunidad son severamente castigados. Es claro entonces que la moral dentro de la comunidad no es igual si no que se aplica conforme al rol que se ocupa dentro de esta.

Este análisis es el que lleva a Lariguet (2014) a concluir que la figura de autoridad, encargada

"Los adeptos cultos conforman un poderoso cerebro al interior de la organización, como un grupo de oficiales de élite de un ejército. El que dirige es el líder, el núcleo básico de la doctrina. La organización ha adoptado regirse mediante un sistema colegiado." (Murakami, 2011, p. 372, libro I).

24. Lariguet (2014) enfoca su estudio crítico de la obra de Murakami poniendo de presente que su objetivo es explorar cuál es el significado de moralidad en 1Q84. El autor hace referencia al mito platónico del anillo de Giges. Con esto pretende generar la discusión acerca de cuáles son los criterios que determinan la moralidad de un sujeto que posee un poder sobrehumano. O si, por el contrario, sus actuaciones no deben ser catalogadas como correctas o injustas dadas sus cualidades especiales. Este análisis lo hace contrastando la idea de que todos los superhéroes que poseen poderes extraordinarios siempre los dirigen hacia la persecución del bien (la verdad y la justica), con la respuesta que ofrece Platón cuando concluye que es más feliz un hombre justo que es condenado a prisión por actos que cometió y se presumen injustos, que un hombre injusto que vive en plena libertad. Y aplica el ejemplo de Giges, ya que el protagonista de este relato se asemeja a Fukada en la medida en que ambos poseen poderes sobrenaturales y por tanto sus actuaciones tienen implicaciones diferentes a las de los humanos normales. Considera que este análisis es importante porque la única forma de garantizar que dentro de una comunidad se asegure la búsqueda del bien, la justicia y la verdad, es a través de la postulación de una teología o escatología que presuponga la existencia de un dios o una autoridad carismática que asevere que todo mal será condenado. Lo que significa que, de las actitudes correctas o incorrectas del líder sobrehumano dependerá el bienestar dentro de la sociedad. Como ejemplo de ello, el autor explica que Aomame es una renunciante a la fe exacerbada de sus padres (Testigos de Jehová) pero al final de la trilogía recupera una vieja oración (venga a nosotros tu reino) con el propósito de regresar a un mundo donde la moral esté garantizada. 
de la organización de la sociedad, se escapa de los criterios de moralidad. ${ }^{25}$ En consecuencia, los mandatos del líder serán obedecidos independientemente de que puedan ser vistos como incorrectos o injustos, ya que su legitimidad radica en que es una autoridad carismática que posee poderes maravillosos, que escapan a la esfera de lo terrenal. Por ello se espera que sus actuaciones tengan implicaciones diferentes a las de los humanos normales. En consecuencia, las personas escogen obedecer sus preceptos en razón de la fe que le predican, dotando de legitimidad su ejercicio del poder.

Refiriéndonos al análisis hecho en las novelas utilizando la teoría de Weber es preciso mencionar que el límite que encuentra el derecho en este punto es que la estratificación y división social generan resentimiento e inconformidad por parte de los miembros de las clases y estamentos inferiores. El resultado es la necesidad de rebelión y descontrol por parte de las personas, movidos por sentimientos de odio y desagrado hacia aquellos que poseen más dinero y una mejor calidad de vida. Este tipo de sensaciones se ven reflejadas en los personajes principales de las dos novelas. Por ejemplo, en 1984, Julia deja ver al lector cómo ella se siente diferente a los miembros del Partido Interior y, por tanto, ajena a su realidad. Esta barrera social es lo que provoca su odio y rebeldía contra el partido, lo cual se evidencia cuando se acerca a Winston por primera vez,

-Algo en tu cara. Me decidí a arriesgarme. Conozco en seguida a la gente de la acera de enfrente. En cuanto te vi supe que estabas contra ellos. -Ellos, por lo visto, quería decir el Partido, y sobre todo el Partido Interior, sobre el cual hablaba Julia con un odio manifiesto. ${ }^{26}$ A él no le disgustaba eso, puesto que era un síntoma de la rebelión de la joven contra el Partido y sus métodos. (Orwell, 1949, p. 69).

El método de rebelión adoptado por los personajes de 1984 es el unirse a la Hermandad, ${ }^{27}$

25. Es por eso que el autor sostiene la tesis de que en 1084 no existe un modelo de moralidad si no que esta es indeterminada (Lariguet, 2014, p. 120). Es decir, la moral guarda silencio frente a cómo evaluar ciertos comportamientos humanos, sobre todo de quienes poseen poderes sobrenaturales. Para explicar esta idea se remite a la escena en la cual Aomame conoce a Fukada (momentos antes de asesinarlo) y este le explica que él "no sabe si esto a lo que llaman la Little People es bueno o malo", puesto que "trasciende la capacidad de definición y entendimiento", ellos viven desde tiempos inmemoriales "antes de que el bien y el mal se encontrasen establecidos". Bajo la misma línea de reflexión, Aomame piensa que "Fukada había cometido actos que atentaban contra la moralidad". Sin embargo Fukada "no era una persona normal y corriente en diversos sentidos, esta falta de normalidad podía considerarse como algo que trascendía los criterios del bien y del mal" (Lariguet, 2014, p. 113, citando a Murakami, 2012). Lo que significa que los personajes comprenden que existen comportamientos que no pueden ser evaluados moralmente porque los criterios de bien y mal no tienen aplicación y por tanto la moral es indeterminada.

26. “Le asombraba la rudeza con que hablaba Julia. Se suponía que los miembros del Partido no decían palabrotas, y el propio Winston apenas las decía como no fuera entre dientes. Sin embargo, Julia no podía nombrar al Partido, especialmente al Partido Interior, sin usar palabras de esas que solían aparecer escritas con tiza en los callejones solitarios" (Orwell, 1949, p. 69).

27. "Quizás, después de todo, resultaran ciertos los rumores de extensas conspiraciones subterráneas; quizás existiera de verdad la Hermandad. Era imposible, a pesar de los continuos arrestos y las constantes confesiones y ejecuciones, estar seguro de que la Hermandad no era sencillamente un mito" (Orwell, 1949, p. 12). 
una sociedad clandestina que realiza acciones para sabotear al partido. Dentro de las tesis que sostiene la Hermandad para conseguir adeptos está la propuesta de una sociedad sin clases sociales. Podemos analizar que el derecho no puede mantener el control sobre la sociedad porque es estratificante, lo cual genera inconformidad y rebeldía. De manera que la propuesta para conseguir el control dentro de una comunidad es mantener a los individuos en condiciones de equidad, es decir, abolir las clases y estamentos sociales. Es por ello que Winston, inspirado en el libro Teoría y práctica del colectivismo oligárquico, de Emmanuel Goldstein, apoya la idea de que

si hay alguna espera está en los proles. Si los proles, pudieran darse cuenta de su propia fuerza, no necesitarían conspirar. Les bastaría con encabritarse como un caballo que se sacude las moscas. Si quisieran podrían destrozar el Partido mañana por la mañana. Desde luego, antes o después se les ocurrirá. (Orwell, 1949, p. 41).

En este sentido, Galván (2014), en el ensayo titulado Actualidad, polémica y consenso crítico sobre 1984, resalta que Orwell en 1984 propone la creación de una sociedad $\sin$ clases $^{28}$ donde se defienda la libertad y la dignidad del ser humano como pilares fundamentales. De allí que, interpreta, la solución propuesta por Orwell para terminar con la estratificación y discriminación social resida en el mismo pueblo, "los proles" y no en los miembros del partido los cuales son seres "insensibles". Entiende que 1984 no debe ser catalogada como una novela que propugna por un orden social derechista y antisoviético, sino como la propuesta de un orden social basado en el socialismo sin partidos (p. 30).

En lo referente a la autoridad es necesario sostener que un sistema jurídico caracterizado por ser un estado totalitario, regido por una autoridad carismática, también encuentra un límite para mantener el control social. Este límite radica en que, a pesar de ser una autoridad legitimada para dictar las normas, esta no siempre es aceptada y obedecida por todos. Es decir, su carisma no es suficiente para subyugar a todas las personas. Quienes no creen en sus cualidades extraordinarias y le veneran, se abstraen de su esfera de control. Este es el caso de Winston y Julia, quienes aparentan amar al Gran Hermano pero en su fuero interno lo desprecian. Es por esto que en situaciones como durante los dos minutos del odio simulan cumplir con la tarea de detestar a Goldstein, pero en realidad su odio se ve reflejado hacia el mismo Gran Hermano. ${ }^{29,30}$ Por tanto, se tiene que el derecho se ve limitado porque su

28. Galván sostiene que el odio de Orwell por la aristocracia y la división social se remonta a su infancia y juventud, tiempo en el cual su padre recibía un modesto salario de funcionario por ser miembro del Indian Civil Service, razón por la cual se sentía humillado y frustrado estudiando en St. Cyprians junto con hijos de familias adineradas.

29. Refiriéndose al partido: “Sé en qué estás pensando. Conozco tu asco, tu odio, tu disgusto." (Orwell, 1949, p. 11).

30. "Su pluma se había deslizado voluptuosamente sobre el suave papel, imprimiendo en claras y grandes mayúsculas lo siguiente: ABAJO EL GRAN HERMANO.” (Orwell, 1949, p. 12). 
legitimidad no puede radicar solamente en la confianza y carisma que inspira una persona.

\section{CONCLUSIÓN}

Este texto se ha concentrado en estudiar las nociones de validez y justicia, legitimidad y autoridad, fin de la pena y la relación entre ordenamiento jurídico, estructura social y su control en las novelas 1984 y 1Q84. El fin ha sido determinar cuál es la respuesta que estas obras ofrecen a la pregunta: ¿Cuáles son los límites del derecho para ejercer y mantener el control social? Lo anterior, en razón a que al lado del derecho, el cual tradicionalmente se ha utilizado como un mecanismo para la organización del poder dentro de las comunidades, se halla la literatura. Esta última, además de ser una expresión artística, sirve como herramienta para el análisis de los postulados normativos pues exterioriza la opinión de personas que están sujetas a su dominio pero son ajenas a la educación del jurista. La literatura puede, así, problematizar el contenido del derecho e imaginar un infinito universo de posibilidades y eventos donde este puede resultar incompleto e ineficiente. Esta idea es expresada por Lenio Luiz Streck cuando dice:

Conforme ha demostrado la historia, en todos los regímenes totalitarios vividos en la modernidad, dos figuras siempre estuvieron presentes: la del jurista (de guardia), que ha defendido la legitimidad del ordenamiento en vigor, y la del poeta, que en la clandestinidad o, aún en la cárcel, ha denunciado las in- justicias y atrocidades del poder. (Citado pot Karam y Malgalhães, 2009, p. 208).

Es por esta razón que la literatura realiza un aporte importante a la teoría jurídica y a la filosofía del derecho, pues sus obras valen como instancia crítica de los sistemas legislativos opresores y antidemocráticos, semejantes a los presentados por Orwell y Murakami.

Al analizar las novelas objeto de estudio desde un enfoque jurídico, se concluye cuáles son los límites que estas determinan que posee un sistema legislativo, judicial y autoritario, para mantener la estabilidad y el orden dentro de una comunidad. Primero, el derecho, que goza de validez formal y material, al ser creado por la autoridad legítima y a través del procedimiento establecido para ello, no es suficiente para mantener el control y represión social pues tiene como límite la justicia. Esto significa que la norma no será obedecida por los miembros de la comunidad si estos determinan que es injusta, tras evaluar su contenido a la luz de sus criterios de moralidad. Es así como, en las dos obras estudiadas, una norma que carece de justicia no podrá ser utilizada como un mecanismo idóneo de control social pues los individuos actuarán de acuerdo con lo que individualmente consideran correcto, en aras de salvaguardar un bien jurídico superior.

Lo anterior conduce a un segundo punto respecto de las nociones de proceso judicial, pena y criminal. El derecho no siempre resulta ser una técnica de control social, ya que dentro de un régimen totalitario, como el presentado en 
1984 donde existe un derecho penal retributivo, de autor, y que sanciona la peligrosidad, este no resulta efectivo pues no crea los incentivos necesarios para evitar la criminalidad. El derecho no puede prever la infinidad de valores y bienes jurídicos que cada individuo en particular considera más valiosos y, por lo tanto, una razón justa para delinquir y asumir las consecuencias jurídicas. Es decir, si el derecho pretende controlar todas las actuaciones humanas ha de ser atípico y arbitrario. Asimismo, como lo exponen las novelas de Orwell y Murakami, el derecho cae en una paradoja, pues requiere de descontrol y del comportamiento anómalo para poder intervenir con su facultad sancionadora en busca de control.

En la novela del autor nipón, a diferencia de 1984, se estudia un derecho penal preventivo y no retributivo, que aparece igualmente limitado porque se enfoca en la comunidad y no en el individuo. Por esta razón su esfera de control le es ajena al delincuente, quien como sujeto individual no sufre las consecuencias directas y por ello se sustrae de una sanción.

En tercer lugar, el derecho, al crear división y estratos sociales, provoca inconformidad y odio entre los miembros de las clases inferiores. El efecto es la rebeldía y el descontrol por parte de las personas que buscan desobedecer los mandatos de quienes se proclaman superiores. Por este motivo, el derecho no resulta idóneo para crear estabilidad y seguridad. La propuesta en estos dos ejemplos literarios es un modelo de sociedad sin clases ni estamentos sociales, donde los individuos estén en condiciones permanentes de equidad.

Cuarto, la legitimidad de una autoridad no puede recaer únicamente en su carisma, pues en toda sociedad habrá sujetos que crean fielmente en sus cualidades extraordinarias y por tanto no se sientan atraídos y subordinados a esta. De allí que existan personas que rindan obediencia, pero esta solo ha de ser aparente, fomentándose así el descontrol.

Para terminar este análisis he de destacar que el estudio del derecho y la literatura resulta provechoso porque las normas, los mecanismos de control, la ley y "las Constituciones políticas pueden ser leídas, en su gran mayoría, como un verdadero e importante relato de la historia de los valores fundantes de una determinada comunidad" (Karam y Malgalhães, 2009, p. 201). Por esta razón Dominique Rousseau sostiene que "las Constituciones son las mitologías de las sociedades modernas" (citado por Karam y Malgalhães, 2009, p. 201), porque son el pilar fundamental de un sistema legal que dota de sentido la vida en comunidad al ser una compilación de su historia y costumbres. Así pues, si las Constituciones pueden ser catalogadas como las mitologías de las sociedades modernas, también podemos catalogar a la literatura como las piezas documentales a partir de las cuales se puede reconstruir y estudiar el sistema jurídico y legal de una comunidad. He ahí la importancia de su estudio. 
Referencias

1. Aguiar e Silva, J. (2001). A prática judiciária entre direito e literatura. Coimbra: Almedina.

2. Bobbio, N. (2004). El problema del positivismo jurídico. Buenos Aires: Editorial Universitaria.

3. Bobbio, N. (1993). Teoría general del derecho. Madrid: Debate S. A.

4. Bonilla, D. (2005). Justicia y derecho. El engaño y la justicia de Selb. Obtenido de icesi: https://www.icesi.edu.co/precedente/ediciones/2005/06_Daniel_Bonilla.pdf

5. Dávalos, L. (2012). Metáforas del poder $y$ del amor en 1084. Obtenido de caracas1067: https://caracas1067.wordpress. com/2012/04/11/metaforas-del-poder-ydel-amor-en-1q84-2/

6. De Aquino, T. (1989). Suma Teológica 11. Parte 1-11. (Segunda ed.). (J. M. Rodríguez Arias, Trad.). Madrid: Biblioteca de Autores Cristianos.

7. De Hipona, S. (1982). El libre albedrío (S. Santamarte del Río, Ed., \& E. Seijas, Trad.). Madrid: Biblioteca de Autores Cristianos.

8. Deutscher, I. (1974). 1984 - The Mysticism of Cruelty. En R. Williams, George Orwell a collection of critical essays. Englewood Cliffs, Nueva Jersey: Prentice-Hall.

9. Durán Migliardi, M. (2011). Teorías absolutas de la pena: origen y fundamentos. Conceptos y críticas fundamentales a la teoría de la retribución moral de Immanuel Kant a propósito del neo-retribucionismo y del neo-proporcionalismo en el derecho penal actual. Revista de Filosofía, 67, 123-144. Obtenido de scielo: http:// www.scielo.cl/scielo.php?pid=S0718$43602011000100009 \&$ script $=s c i_{-}$ arttext\#nota14.

10. Fairbairns, Z. (2001). 1984 came and went. En A. Lázaro, The Road from George: his achievement and legacy. Bern [u.a.]: Lang.

11. Ferrajoli, L. (s.f.). Noberto Bobbio, teórico del derecho y la democracia. Obtenido de juridicas: http://www.juridicas.unam.mx/ publica/librev/rev/facdermx/cont/253/ pr/pr3.pdf

12. Feuerbach, P. J. A. von. (1989). Tratado de derecho penal común vigente en Alemania. Buenos Aires: Hammurabi.

13. Galván, F. (2014). Actualidad, polémica y consenso crítico sobre 1984. En G. Orwell, 1984 (págs. 9-61). Caracas: Planeta.

14. García Cavero, P. (s.f.). Acerca de la función de la pena. Obtenido de incipp: http://incipp.org.pe/modulos/documentos/archivos/funcionpena.pdf 
15. Garofalo, R. (1912). La criminología: estudio sobre la naturaleza del crimen y teoría de la penalidad. Madrid: Daniel Jorro.

16. González, G. y González, M. (2007). La teoría criminalística en la individualización de la pena. Obtenido de: http://www.facso. uchile.cl/-publicaciones/moebio/-29/gonzalez.pdf

17. Karam Trindade, A. y Magalhães Gubert, R. (2009). Derecho y literatura. Acercamientos y perspectivas para repensar el derecho. Revista Electrónica del Instituto de Investigaciones Jurídicas y Sociales Ambrosio Lucas Gioja, 3(4), 164-213. Obtenido de derecho: http://www.derecho.uba.ar/ revistagioja/articulos/R0004A003_0010_ investigacion.pdf

18. Lariguet, G. (2014). Más allá del bien y del mal. Un análisis de la obra de Haruki Murakami. Devenires, XV(29), 105-126.

19. Murakami, H. (2011). 1Q84. Barcelona: TusQuets Editores.

20. Murakami, H. (2012). 1Q84. Buenos Aires: Editorial Tusquets.

21. Newburn, T. (2007). Classicism and positivism. En T. Newburn, Criminology (págs. 114-129). Cullompton: Willan Publishing.

22. Nussbaum, M. (2005). El conocimento del amor: ensayos sobre filosofía y literatura. Madrid: Machado.
23. Orwell, G. (1949). 1984. Caracas: Planeta.

24. Pergolesi, F. (1927). II diritto nella letteratur. Archivio Giuridico "Filippo Serafini", XCVII(I), 61-104.

25. Posner, R. (1998). Law and Literature. Cambridge, Mass.: Harvard University Press.

26. Radbruch, G. (1946). Gesetzliches Unrecht und übergesetzliches Recht., Band 3. Rechtsphilosophie 111. A. Kaufmann (Hg.), Heidelberg, Müller.

27. Roxin, C. (1999). Derecho penal, Parte general (Segunda ed., t. I). Madrid: Editorial Civitas.

28. Salazar Ugarte, P. (2011). El constitucionalismo de Norberto Bobbio: un puente entre el poder y el derecho. Cuestiones Constitucionales, (14), 177-201.

29. Santiago, J. M. (2003). 184, de George Well. Conferencia impartida durante la Feria del Libro de Cádiz de 2003, en el marco de la Jornada de la Ciencia-Ficción organizada por el Ayuntamiento y coordinadas por Luis G. Prado, así como en la HispaCon Xatafi 2003. Obtenido de bibliopolis: http://www.bibliopolis.org/articulo/1984. htm

30. Seoane, J. (s. f.). La doctrina clásica de la lex iniusta y la fórmula de Radbruch. Un ensayo de comparación. Obteni- 
do de ruc.udc: http://ruc.udc.es/bitstream/2183/2163/1/AD-6-36.pdf.

31. Talavera, P. (2006). Derecho y literatura. Granada: Editorial Comares.

32. Taylor, I. (2007). La criminología clásica y la revolución positivista - Contribución a una teoría social de la conducta desviada (Tercera ed.). Buenos Aires: Amorrortu.
33. Weber, M. (s. f.). Economía y sociedad. Obtenido de fcpolit: http://www.fcpolit.unr. edu.ar/teoriapolitica/files/2014/10/Weber.Divisi\%C3\%B3n-del-poder-en-la-comunidad.pdf

34. West, R. (1988). Communities, Texts, and Law: Reflections on the Law and Literature Movement. Yale Journal of Law \& the Humanities, I, 128-156. 